\title{
Privacy Level in Private Community Pharmacies in Saudi Arabia: A Simulated Client Survey
}

\author{
Hani M. J. Khojah \\ Department of Clinical and Hospital Pharmacy, College of Pharmacy, Taibah University, Madinah, Saudi Arabia \\ Email: hkhojah@taibahu.edu.sa
}

How to cite this paper: Khojah, H.M.J. (2019) Privacy Level in Private Community Pharmacies in Saudi Arabia: A Simulated Client Survey. Pharmacology \& Pharmacy, 10, 445-455.

https://doi.org/10.4236/pp.2019.1010036

Received: September 18, 2019

Accepted: October 19, 2019

Published: October 22, 2019

Copyright (อ 2019 by author(s) and Scientific Research Publishing Inc. This work is licensed under the Creative Commons Attribution International License (CC BY 4.0).

http://creativecommons.org/licenses/by/4.0/

\section{(c) (i) Open Access}

\begin{abstract}
Background: Maintaining privacy during patient counseling is critical, especially with respect to sensitive client issues. In general, community pharmacy practice in Saudi Arabia is considered substandard in several aspects, particularly with respect to the privacy it offers to pharmacy clients. However, to date, maintenance of privacy in Saudi Arabian community pharmacies has not been studied using a practical, measurable method. Objective: This study investigates the level and quality of privacy offered by community pharmacies in Madinah, Saudi Arabia. Methods: This study randomly selected 80 pharmacies, which were visited by a simulated client and a simulated customer who were instructed to engage in a standard scenario. During each pharmacy visit, the simulated client asked the on-duty pharmacist about the correct use of a medication intended for a vaginal disease. The simulated customer pretended to look for a nonmedical product on the shelf nearest to where the client-pharmacist consultation took place and observed whether the conversation was audible. Further, privacy facilities and pharmacist behaviors were documented. Results: A designated consultation area was found in only one pharmacy; however, it was not used and not designed as separate from the pharmacist's counter. Although a designated waiting area was found in the same pharmacy, it was located too close for privacy to be maintained. Other physical measures of privacy were unavailable in all the other pharmacies. Regarding the simulated client-pharmacist consultation, the conversation was audible to the simulated customer in $63 \%$ of the pharmacies. Further, in most of the visited pharmacies, there was only one pharmacist on duty. Finally, a female pharmacist was found in only one pharmacy. Conclusions: The study concludes that a critical insufficiency in privacy exists in community pharmacies in Saudi Arabia. It reveals that most pharmacies must be infrastructurally redesigned to provide acceptable privacy levels. Further, the number of
\end{abstract}


on-duty pharmacists should be increased, and pharmacies should employ more female pharmacists.

\section{Keywords}

Privacy, Patient Counseling, Patient Education, Community Pharmacy, Saudi Arabia

\section{Introduction}

Often, the concept of privacy and the accepted levels of privacy provision differ according to the situation, as well as from one person to the other. However, in pharmacy practice, the minimum acceptable level of privacy during a pharmacist-patient counseling session is one that ensures that the patient can have a one-to-one communication with the pharmacist without being overheard by others [1]. Probably, patients experience adequate privacy levels at physicians' offices since, typically, there are no other patients in the examination room at the same time. However, in pharmacies, several customers may be in the vicinity at any given time [2].

Since community pharmacies are expected to be crowded, perhaps the best privacy practice is the availability of an appropriately isolated room or office that ensures the client and/or caregiver can talk with the pharmacist without being heard or seen by others. If a completely separate room cannot be provided, privacy may be ensured by assigning a separate area for counseling at the end of the pharmacy counter, which is separated by a physical barrier with a sign denoting it as a private consultation area. However, sometimes, due to a lack of space, a pharmacist can offer private counseling only by establishing the waiting line at an appropriate distance from the counter, taking the client to a more secluded area in the pharmacy, or even lowering his or her voice while leaning toward the client [3]. Further, telephonic and online consultations have been determined to be possibly better alternatives when privacy is difficult to be established in the pharmacy setting [4].

Private counseling at pharmacies is particularly critical when the dispensed medication is to be used to treat mental illnesses or sensitive conditions, such as diseases of the urogenital system, or when the medication must be applied to a discrete area of the body [3] [5] [6] [7]. However, even when clients require counseling for other, less sensitive issues, such as cardiovascular screening services, smoking cessation, weight control, and bronchial asthma, they may require privacy [8]-[12]. Moreover, privacy seems to be an important consideration for some customers even when obtaining information from the pharmacist regarding over-the-counter medications [13].

The issue of privacy maintenance at community pharmacies is a global one, since, worldwide, patients tend to seek advice from their community pharmacists regarding various treatments and minor ailments [14]. For example, although 
most customers in the United Kingdom stated that the provision of privacy was good, they also mentioned the need to maintain a higher level of privacy since, often, the private areas designated for consultation were underutilized and private rooms were either not very customer friendly or used for other purposes [1] [15]. In Australia, one study found that pharmacy staff was advised to receive more training to enhance the maintenance of privacy to comply with national requirements, since most pharmacist-patient interactions were found to occur in the presence of other customers close to the pharmacy counter [15]. Similarly, in the United States, a study found an increased chance for disclosure of confidential patient information, due to an insufficiency in the level of privacy offered [3]. Interestingly, a study from Japan showed that approximately $50 \%$ of patients were willing to pay an average of 400 yen per pharmacy consultation if privacy was ensured [16].

In Saudi Arabia, a country witnessing a rapid growth in its pharmaceutical service industry, a survey conducted in 2004 revealed that customers of community pharmacies in the capital city of Riyadh were concerned about the insufficient privacy offered during consultations [17]. Although 14\% of the customers in that study reported that private areas for counseling were available, the structure or description of such private areas was not mentioned in the study. Further, approximately $59 \%$ of the customers stated that the pharmacist spoke to them quietly across the counter while discussing private issues. The lack of appropriate privacy maintenance at community pharmacies in Saudi Arabia has been examined in several other surveys conducted between 2013 and 2015, as well, in which up to $94 \%$ of customers complained about the lack of privacy and requested the presence of private areas in community pharmacies [18] [19] [20].

The aforementioned surveys conducted in Saudi Arabia have only measured the attitudes of customers and/or pharmacists regarding a variety of services provided by community pharmacies. In addition, other previous studies have revealed the countrywide similarity in the quality of services provided by community pharmacies [21] [22] [23] [24] [25]. However, no study has practically and objectively investigated the level of privacy provided by Saudi Arabian community pharmacies. Therefore, this study aims to investigate the level of privacy provided during client-pharmacist consultations by private community pharmacies in Madinah, a major Saudi Arabian city that represents the nationwide similarity in the quality of services provided by the country's community pharmacies.

\section{Methods}

\subsection{Ethical Approval}

Informed consent could not be obtained since this is a simulated client study and telling the pharmacist that the pharmacy will be investigated might affect the behavior of the pharmacist. This waiver of informed consent was approved by Taibah University's Research Ethics Committee, Madinah, Saudi Arabia. 


\subsection{Selection of Pharmacies}

A list of all pharmacies $(n=353)$ and their locations was obtained from the local Directorate of Health Affairs in Madinah. The pharmacies were coded 1 through 353, and the list was randomly scrambled using Microsoft Excel 2016 (Microsoft Company, the United States). Then, the first 80 pharmacies were selected for inclusion in the study. If a pharmacy could not be located or the business had closed down, it was replaced by the nearest one in the neighborhood, provided it was not already included in the selected 80 pharmacies. Seven pharmacies were replaced since they either were not found or had closed down. All the pharmacies were visited during daytime working hours in January 2019.

\subsection{Participants}

The researcher requested the voluntary participation of four pharmacy students to form two teams so that the first team has two males and the second team has two females. Members of each team should act as they are separate shoppers who do not know each other. Each member of each team was trained to behave in a scenario as either a simulated client or a simulated customer. The simulated client was instructed to engage the pharmacist in a consultation, whereas the simulated customer was required to remain in the vicinity of the consultation. Each team was assigned to visit one half of the selected pharmacies $(n=40)$.

\subsection{Pharmacy Visit Scenario}

For each pharmacy visit, the simulated client was instructed to enter the pharmacy and approach the pharmacist when the latter was not busy with other customers. The simulated customer was instructed to remain at the nearest shelf to the pharmacy counter, pretending to be searching for a nonmedical item while determining whether the conversation between the simulated client and pharmacist could be overheard. The simulated client was instructed to show the pharmacist a package of vaginal tablets, claiming that it had been prescribed for his or her mother without instructions on how to use it. The simulated client was further instructed to ask whether the tablet could be broken since it is large and difficult to be swallowed by mouth. The simulated client and the simulated customer were asked to note the pharmacist's response and also observe the level of privacy maintained by the pharmacist during the consultation. Finally, the simulated client was instructed to thank the pharmacist and leave, followed by the simulated customer.

\subsection{Survey Form}

Immediately after leaving a pharmacy, members of each team completed a survey form. The header of the form included the pharmacy name and code, date and time of visit, and names of the team members. The availability and structure of the counseling area and all the expected responses of the pharmacist were included as checkboxes in the body of the form. A space for additional notes was 
provided at the end of the form. Subsequently, the group members folded and stapled the header to blind the researcher from its details. Finally, all the forms were collected by the teams, randomly shuffled, and returned to the researcher.

\subsection{Confidentiality}

It is noted that personal information was not collected from any pharmacist, and pharmacy names will be kept confidential, unless they are requested by the relevant authorities in Saudi Arabia.

\subsection{Data Analysis}

Simple descriptive analyses of frequencies and ratios were conducted on the survey results.

\section{Results}

An examination of the survey form responses revealed that an isolated area or office for client-pharmacist consultation was not observed in any of the 80 visited pharmacies. Further, a designated area for consultations was available in only one of the pharmacies. This designated area was observed to be an extension of the dispensing and cashier counter and separated from the counter only by a very short glass partition, which made the client-pharmacist conversation easily audible to others. Moreover, the designated area was not used during the interaction and the conversation was audible to the simulated customer. In addition, a waiting area with an adequate number of chairs was found to be available in only this pharmacy. However, privacy was not maintained since the chairs were placed directly in front of the counter. Designated waiting lines located away from the counter were not observed in any pharmacy. In one pharmacy (1.3\%), the pharmacist asked the simulated female client to accompany him to a quieter area of the pharmacy for consultation. In another instance, due to the small size of the pharmacy, the pharmacist asked the female client to wait until the other customers (including the simulated customer) had left (1.3\%). In all the other pharmacies, counseling was offered at the general dispensing and cashier counter in the presence of other customers nearby; however, in $35 \%$ of the pharmacies, the pharmacist leaned closer to the simulated client to maintain the privacy of the consultation. In $63 \%$ of the pharmacies, the client-pharmacist interaction was overheard by the other member of the team, and only $37 \%$ of the pharmacies offered sufficient privacy for the consultation to not be overheard by the simulated customer. Table 1 summarizes the different levels of privacy offered by the pharmacists.

Regarding the content of counseling offered by the pharmacists, $94 \%$ of the pharmacists, regardless of the level of privacy provided by them, provided the correct instructions regarding the medication (i.e., the tablet was for vaginal use). However, three pharmacists agreed that the patient could break the tablet into smaller pieces and consume it orally. Finally, two pharmacists declined to 
Table 1. Different levels of privacy offered by the visited pharmacies.

\begin{tabular}{lccc}
\hline \multicolumn{1}{c}{ Level of privacy } & $\begin{array}{c}\text { With male clients } \\
(\mathbf{4 0} \text { pharmacies }) \\
\mathbf{n}(\%)\end{array}$ & $\begin{array}{c}\text { With female clients } \\
(\mathbf{4 0} \text { pharmacies }) \\
\mathbf{n}(\%)\end{array}$ & $\begin{array}{c}\text { With all clients } \\
(\mathbf{8 0} \text { pharmacies }) \\
\mathbf{n}(\%)\end{array}$ \\
$\begin{array}{l}\text { The client was taken to a quieter area in the pharmacy where the simulated } \\
\text { customer was unable to hear what was said }\end{array}$ & $0(0 \%)$ & $1(2.5 \%)$ & $1(1.3 \%)$ \\
$\begin{array}{l}\text { The pharmacist leaned toward the client and lowered his/her voice so that } \\
\text { the simulated customer was unable to hear what was said }\end{array}$ & $23(57.5 \%)$ & $5(12.5 \%)$ & $1(2.5 \%)$ \\
$\begin{array}{l}\text { The client was asked to wait until other customers had left (the simulated } \\
\text { customer left) }\end{array}$ & $0(0 \%)$ & $17(42.5 \%)$ & $33(82.5 \%)$
\end{tabular}

provide any information and told the female client to consult a gynecologist regarding the appropriate use of the medication. Table 2 depicts the contents of the counseling and levels of privacy offered by the pharmacists.

It is noted that all pharmacists, except one, were men, and the only female pharmacist had a male client. Further, the female pharmacist explained the correct use of the tablets while leaning toward the client and lowering her voice so that the other member of the client group could not hear what was said.

\section{Discussion}

This study is the first to examine the provision of privacy at private community pharmacies in Saudi Arabia in an objective and practical manner based on simulated client visits. Among the 80 pharmacies visited, a designated counseling area was found to be available in only one pharmacy, and even this area was found unsatisfactory and unutilized. Further, more than $60 \%$ of the client-pharmacist consultations regarding a sensitive issue were audible to others inside the pharmacies. A similar finding is expected in community pharmacies countrywide due to two reasons: First, most of the cities have several pharmacy chains, which are expected to follow the same pattern of practice, and more than $50 \%$ of the pharmacies visited in this study belong to such chains. Second, according to several studies conducted in several main cities of the country, the quality of practice and services provided by private community pharmacies appears to be similar nationwide [17]-[25]. Therefore, maintenance of privacy is a major problem affecting private community pharmacies in Saudi Arabia.

Although the pharmacies included in this study were visited during normal daytime working hours, only one pharmacist was on duty in nearly all the pharmacies. This situation makes it difficult for the pharmacist to converse privately with every client, particularly since waiting areas and designated waiting lines are unavailable, in general. Therefore, community pharmacies in Saudi Arabia are encouraged to increase the number of pharmacists in each pharmacy and restructure the pharmacy space to offer more privacy for client-pharmacist consultations. It is noted that even the redesign of pharmacy counters to enable one-to-one conversations of clients with pharmacists would enhance the clients' 
Table 2. Contents of counseling associated with the levels of privacy offered by pharmacists.

\begin{tabular}{|c|c|c|c|}
\hline Information given by the pharmacist & $\begin{array}{c}\text { With male clients } \\
\text { (40 pharmacies) } \\
\text { n (\%) }\end{array}$ & $\begin{array}{c}\text { With female clients } \\
(40 \text { pharmacies }) \\
\text { n (\%) }\end{array}$ & $\begin{array}{c}\text { With all clients } \\
(80 \text { pharmacies }) \\
n(\%)\end{array}$ \\
\hline \multicolumn{4}{|l|}{ The correct method of use was provided } \\
\hline Heard by the simulated customer & $16(40 \%)$ & $31(77.5 \%)$ & $47(58.8 \%)$ \\
\hline Not heard by the simulated customer & $23(57.5 \%)$ & $5(12.5 \%)$ & $28(35 \%)$ \\
\hline \multicolumn{4}{|c|}{$\begin{array}{l}\text { The wrong method of use was provided (i.e., tablets can be broken and } \\
\text { swallowed by mouth) }\end{array}$} \\
\hline Heard by the simulated customer & $1(2.5 \%)$ & $1(2.5 \%)$ & $2(2.5 \%)$ \\
\hline Not heard by the simulated customer & $0(0 \%)$ & $1(2.5 \%)$ & $1(1.3 \%)$ \\
\hline \multicolumn{4}{|c|}{$\begin{array}{l}\text { The client was requested to consult a gynecologist to obtain the relevant } \\
\text { information }\end{array}$} \\
\hline Heard by the simulated customer & $0(0 \%)$ & $2(5 \%)$ & $2(2.5 \%)$ \\
\hline Not heard by the simulated customer & $0(0 \%)$ & $0(0 \%)$ & $0(0 \%)$ \\
\hline
\end{tabular}

perception of privacy [26]. Alternatively, pharmacies might consider facilitating client-pharmacist consultations through e-mail, telephone, or online chat sessions, since these options have been proved to ensure privacy [4].

Currently, female pharmacists are not typically employed by Saudi Arabian private community pharmacies, except in certain places such as private hospitals, shopping centers, or airports. According to the cultural norms of Saudi Arabia and, perhaps, other Muslim countries, as well, the close proximity of women with men or women having private conversations with unfamiliar men is typically considered unacceptable behavior. This may explain why most of the male pharmacists in this study did not lean toward the female clients during the consultation, whereas the behavior of leaning toward the client to ensure privacy was observed when talking to male clients, as seen in Table 1 . This may also explain the behavior of those pharmacists who did not provide the information and asked the female client to visit a gynecologist. This latter response, in addition to the response of those pharmacists who gave wrong information (i.e., the tablet can be broken and swallowed by mouth), may also indicate that they were underqualified. Therefore, by hiring female pharmacists in private community pharmacies in Saudi Arabia in such a way that adheres to the cultural norms, the existing barriers in offering privacy for female customers may be eliminated.

The provision of appropriate privacy in community pharmacy settings in Saudi Arabia is critical to the ongoing development of services, since improved privacy would probably increase customer satisfaction [27]. Further, maintaining privacy in client-pharmacist consultations has been observed to enhance communication quality, patient compliance, and instruction adherence [28]. For community pharmacies that aim to expand their roles to include services of a clinical nature, maintenance of client privacy is essential [29]. In addition, privacy is an important consideration for pharmacies willing to participate in pub- 
lic health services [30]. Finally, the lack of privacy has been found to be a major barrier in facilitating appropriate patient-pharmacist interactions [31].

\section{Limitations of the Study}

In this study, pharmacy selection was performed by the researcher. However, the selection was random, and the identity of the pharmacies was not known to the researcher during the survey form analysis. In addition, the study was conducted in only one city in Saudi Arabia. However, the findings can be extrapolated to the entire country since several earlier studies have addressed the insufficiency or unsatisfactory level of services provided by community pharmacies in the country [17]-[25].

\section{Conclusion}

The study revealed a dramatic deficiency in the provision of privacy during clientpharmacist consultation at private community pharmacies in Saudi Arabia. It was observed that information regarding sensitive issues could easily be overheard by other customers since the pharmacies lacked facilities that ensure privacy. Further, the pharmacist-to-customer ratio was found to be extremely low and the lack of female pharmacists in the practice is likely to negatively impact clientpharmacist consultations owing to the cultural norms of the country associated with interactions between men and women. Regulating authorities are advised to issue specific requirements that include redesigning current community pharmacies to enhance the provision of privacy, using these regulations as guidelines for designing future pharmacies, and increasing the number of both male and female pharmacists in community pharmacies.

\section{Acknowledgements}

The researcher thanks Mr. Abdulrahman Almalki, Mr. Bassam Khoshhal, Ms. Reham Alharbi, and Ms. Razan Mofti for playing the role of simulated clients and customers in this study.

\section{Conflicts of Interest}

The author declares no conflicts of interest regarding the publication of this paper.

\section{References}

[1] Anderson, C., Blenkinsopp, A. and Armstrong, M. (2004) Feedback from Community Pharmacy Users on the Contribution of Community Pharmacy to Improving the Public's Health: A Systematic Review of the Peer Reviewed and Non-Peer Reviewed Literature 1990-2002. Health Expectations, 7, 191-202. https://doi.org/10.1111/j.1369-7625.2004.00274.x

[2] Shah, P.D., Marciniak, M.W., Golden, S.D., Trogdon, J.G., Golin, C.E. and Brewer, N.T. (2018) Pharmacies versus Doctors' Offices for Adolescent Vaccination. Vaccine, 36, 3453-3459. https://doi.org/10.1016/j.vaccine.2018.04.088 
[3] Bednarczyk, R.A., Nadeau, J.A., Davis, C.F., McCarthy, A., Hussain, S., Martiniano, R., Lodise, T., Zeolla, M.M., Coles, F.B. and McNutt, L.A. (2010) Privacy in the Pharmacy Environment: Analysis of Observations from Inside the Pharmacy. Journal of the American Pharmacists Association, 50, 362-367. https://doi.org/10.1331/JAPhA.2010.09001

[4] Hattingh, H.L., Emmerton, L., Ng Cheong Tin, P. and Green, C. (2016) Utilization of Community Pharmacy Space to Enhance Privacy: A Qualitative Study. Health Expectations, 19, 1098-1110. https://doi.org/10.1111/hex.12401

[5] Fejzic, J., Knox, K., Hattingh, H.L., Mey, A., McConnell, D. and Wheeler, A.J. (2017) Australian Mental Health Consumers and Carers Expect More Health Management Information from Community Pharmacy. The International Journal of Pharmacy Practice, 25, 454-462. https://doi.org/10.1111/ijpp.12356

[6] Hattingh, H.L., Kelly, F., Fowler, J. and Wheeler, A.J. (2017) Implementation of a Mental Health Medication Management Intervention in Australian Community Pharmacies: Facilitators and Challenges. Research in Social \& Administrative Pharmacy, 13, 969-979. https://doi.org/10.1016/j.sapharm.2017.05.017

[7] Liekens, S., Smits, T., Laekeman, G. and Foulon, V. (2012) Pharmaceutical Care for People with Depression: Belgian Pharmacists' Attitudes and Perceived Barriers. International Journal of Clinical Pharmacy, 34, 452-459. https://doi.org/10.1007/s11096-012-9628-0

[8] Allan, C., Radley, A. and Williams, B. (2012) Paying the Price for an Incentive: An Exploratory Study of Smokers' Reasons for Failing to Complete an Incentive Based Smoking Cessation Scheme. Journal of Health Services Research \& Policy, 17, $212-$ 218. https://doi.org/10.1258/jhsrp.2012.011084

[9] Naik Panvelkar, P., Armour, C. and Saini, B. (2010) Community Pharmacy-Based Asthma Services-What Do Patients Prefer? The Journal of Asthma, 47, 1085-1093. https://doi.org/10.3109/02770903.2010.514638

[10] Taylor, J., Krska, J. and Mackridge, A. (2012) A Community Pharmacy-Based Cardiovascular Screening Service: Views of Service Users and the Public. The International Journal of Pharmacy Practice, 20, 277-284. https://doi.org/10.1111/j.2042-7174.2012.00190.x

[11] Verma, R.K., Paraidathathu, T., Taha, N.A. and Chong, W.W. (2018) Perceptions of the Malaysian General Public on Community Pharmacy-Based Weight Management Services. Journal of Pharmaceutical Policy and Practice, 11, 17. https://doi.org/10.1186/s40545-018-0146-x

[12] Weidmann, A.E., Cunningham, S., Gray, G., Hansford, D., Bermano, G. and Stewart, D. (2012) Views of the Scottish General Public on Community Pharmacy Weight Management Services: International Implications. International Journal of Clinical Pharmacy, 34, 389-397. https://doi.org/10.1007/s11096-012-9624-4

[13] Seubert, L.J., Whitelaw, K., Boeni, F., Hattingh, L., Watson, M.C. and Clifford, R.M. (2017) Barriers and Facilitators for Information Exchange during Over-the-Counter Consultations in Community Pharmacy: A Focus Group Study. Pharmacy (Basel), 5, E65. https://doi.org/10.3390/pharmacy5040065

[14] Curley, L.E., Moody, J., Gobarani, R., Aspden, T., Jensen, M., McDonald, M., Shaw, J. and Sheridan, J. (2016) Is There Potential for the Future Provision of Triage Services in Community Pharmacy? Journal of Pharmaceutical Policy and Practice, 9, 29. https://doi.org/10.1186/s40545-016-0080-8

[15] Hattingh, H.L., Knox, K., Fejzic, J., McConnell, D., Fowler, J.L., Mey, A., Kelly, F. and Wheeler, A.J. (2015) Privacy and Confidentiality: Perspectives of Mental Health 
Consumers and Carers in Pharmacy Settings. The International Journal of Pharmacy Practice, 23, 52-60. https://doi.org/10.1111/ijpp.12114

[16] Someya, F., Takuma, H., Izumisawa, M. and Shiragami, M. (2009) Patient Needs for Consultation with Pharmacists. Yakugaku Zasshi, 129, 1137-1140.

https://doi.org/10.1248/yakushi.129.1137

[17] Bawazir, S.A. (2004) Consumer Attitudes towards Community Pharmacy Services in Saudi Arabia. International Journal of Pharmacy Practice, 12, 83-89. https://doi.org/10.1211/0022357023718

[18] Al-Arifi, M.N. (2013) Availability and Needs of Herbal Medicinal Information Resources at Community Pharmacy, Riyadh Region, Saudi Arabia. Saudi Pharmaceutical Journal, 21, 351-360. https://doi.org/10.1016/j.jsps.2012.11.004

[19] Al-Arifi, M.N. (2014) Community Pharmacists' Attitudes toward Dispensing Errors at Community Pharmacy Setting in Central Saudi Arabia. Saudi Pharmaceutical Journal, 22, 195-202. https://doi.org/10.1016/j.jsps.2013.05.002

[20] Alotaibi, H.S. and Abdelkarim, M.A. (2015) Consumers' Perceptions on the Contribution of Community Pharmacists in the Dispensing Process at Dawadmi. Saudi Pharmaceutical Journal, 23, 230-234. https://doi.org/10.1016/j.jsps.2014.11.002

[21] Alanazi, A., Alfadl, A. and Hussain, A. (2016) Pharmaceutical Care in the Community Pharmacies of Saudi Arabia: Present Status and Possibilities for Improvement. Saudi Journal of Medicine and Medical Sciences, 4, 9-14. https://doi.org/10.4103/1658-631X.170881

[22] Alfadl, A.A., Alrasheedy, A.A. and Alhassun, M.S. (2018) Evaluation of Medication Counseling Practice at Community Pharmacies in Qassim Region, Saudi Arabia. Saudi Pharmaceutical Journal, 26, 258-262. https://doi.org/10.1016/j.jsps.2017.12.002

[23] Kashour, T.S., Joury, A., Alotaibi, A.M., Althagafi, M., Almufleh, A.S., Hersi, A. and Thalib, L. (2016) Quality of Assessment and Counselling Offered by Community Pharmacists and Medication Sale without Prescription to Patients Presenting with Acute Cardiac Symptoms: A Simulated Client Study. European Journal of Clinical Pharmacology, 72, 321-328. https://doi.org/10.1007/s00228-015-1981-1

[24] Khojah, H.M.J., Pallos, H., Tsuboi, H., Yoshida, N., Abou-Auda, H.S. and Kimura, K. (2013) Adherence of Community Pharmacies in Riyadh, Saudi Arabia, to Optimal Conditions for Keeping and Selling Good-Quality Medicines. Pharmacology \& Pharmacy, 4, 7. https://doi.org/10.4236/pp.2013.45061

[25] Khojah, H.M.J., Pallos, H., Yoshida, N., Akazawa, M., Tsuboi, H. and Kimura, K. (2013) The Quality of Medicines in Community Pharmacies in Riyadh, Saudi Arabia: A Lot Quality Assurance Sampling (LQAS)-Based Survey. Pharmacology \& Pharmacy, 4, 9.

[26] Mobach, M.P. (2009) Counter Design Influences the Privacy of Patients in Health Care. Social Science \& Medicine, 68, 1000-1005. https://doi.org/10.1016/j.socscimed.2008.12.002

[27] Khdour, M.R. and Hallak, H.O. (2012) Societal Perspectives on Community Pharmacy Services in West Bank-Palestine. Pharmacy Practice (Granada), 10, 17-24. https://doi.org/10.4321/S1886-36552012000100004

[28] Beardsley, R.S., Johnson, C.A. and Wise, G. (1977) Privacy as a Factor in Patient Counseling. Journal of the American Pharmacists Association, 17, 366-368. https://doi.org/10.1016/S0003-0465(16)34218-5

[29] Araujo, P.S., Costa, E.A., Guerra, A.A.J., Acurcio, F.A., Guibu, I.A., Alvares, J., Cos- 
ta, K.S., Karnikowski, M.G.O., Soeiro, O.M. and Leite, S.N. (2017) Pharmaceutical Care in Brazil's Primary Health Care. Revista de Saude Publica, 51, 6 s. https://doi.org/10.11606/S1518-8787.2017051007109

[30] Saramunee, K., Krska, J., Mackridge, A., Richards, J., Suttajit, S. and Phillips-Howard, P. (2014) How to Enhance Public Health Service Utilization in Community Pharmacy? General Public and Health Providers' Perspectives. Research in Social \& Administrative Pharmacy, 10, 272-284.

https://doi.org/10.1016/j.sapharm.2012.05.006

[31] Iskandar, K., Hallit, S., Raad, E.B., Droubi, F., Layoun, N. and Salameh, P. (2017) Community Pharmacy in Lebanon: A Societal Perspective. Pharmacy Practice (Granada), 15, 893. https://doi.org/10.18549/PharmPract.2017.02.893 